\title{
Interrogating the 'artificial' divide between health and education for children aged $0-3$ years in urban poor locales in Kenya
}

\begin{tabular}{|c|c|}
\hline \multicolumn{2}{|c|}{$\begin{array}{l}\text { Authors: } \\
\text { Aurelia Munene }^{1} \\
\text { Auma Okwany }^{2}\end{array}$} \\
\hline \multicolumn{2}{|c|}{$\begin{array}{l}\text { Affiliations: } \\
{ }^{1} \text { International Institute of } \\
\text { Social Studies, Erasmus } \\
\text { University Rotterdam, the } \\
\text { Netherlands }\end{array}$} \\
\hline \multicolumn{2}{|c|}{$\begin{array}{l}{ }^{2} \text { Nascent Research and } \\
\text { Development Organization, } \\
\text { the Netherlands }\end{array}$} \\
\hline \multicolumn{2}{|c|}{$\begin{array}{l}\text { Corresponding a } \\
\text { Auma Okwany, } \\
\text { okwany@iss.nl }\end{array}$} \\
\hline \multicolumn{2}{|c|}{$\begin{array}{l}\text { Dates: } \\
\text { Received: } 07 \text { June } 2016 \\
\text { Accepted: } 02 \text { Aug. } 2016 \\
\text { Published: } 03 \text { Dec. } 2016\end{array}$} \\
\hline \multicolumn{2}{|c|}{$\begin{array}{l}\text { How to cite this article: } \\
\text { Munene, A. \& Okwany, A., } \\
\text { 2016, 'Interrogating the } \\
\text { "artificial" divide between } \\
\text { health and education for } \\
\text { children aged 0-3 years in } \\
\text { urban poor locales in Kenya', } \\
\text { South African Journal of } \\
\text { Childhood Education 6(2), } \\
\text { a465. http://dx.doi. } \\
\text { org/10.4102/sajce.v6i2.465 }\end{array}$} \\
\hline \multicolumn{2}{|c|}{$\begin{array}{l}\text { Copyright: } \\
\text { (C) 2016. The Authors } \\
\text { Licensee: AOSIS. This } \\
\text { is licensed under the } \\
\text { Creative Commons } \\
\text { Attribution License. }\end{array}$} \\
\hline \multicolumn{2}{|l|}{ Read online: } \\
\hline 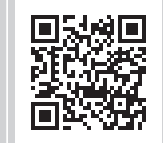 & $\begin{array}{l}\text { Scan this QR } \\
\text { code with your } \\
\text { smart phone or } \\
\text { mobile device } \\
\text { to read online. }\end{array}$ \\
\hline
\end{tabular}

\begin{abstract}
Holistic integrated early childhood policies foster child well-being in the first 3 years of life. The normative framing of Early Childhood Care and Education (ECCE) entrenches segmentation and creates artificial divides between education and health. This segmentation persists yet development processes for children are intertwined and mutually reinforcing. We trouble this artificial divide by drawing on findings from a study which examined the discursive care spaces in an urban poor locale in Kenya. Data were produced through in-depth interviews; participant observation and focus group discussions with caregivers and both state and non-state care providers. Using a socio-ecological lens to analyse intra- and inter-household interactions among caregivers, our analysis exposes the assumptions and silences in ECCE health and education and presents caregivers' rich nuanced experiences and counter accounts. We conclude by calling for the imperative of bridging the divide between and within early childhood health and education to support integrated, adaptive and contextualised policy and practice.
\end{abstract}

\section{Introduction}

\begin{abstract}
... A child is born without barriers. Its needs are integrated and it is we who choose to compartmentalize them into health, nutrition or education. Yet a child cannot isolate its hunger for food, from its hunger for affection or its hunger for knowledge. ... It is this intrinsic strength in the unity of the child that we need to exploit for building ... a more integrated development process. (Margaret Alva, Minister for Women and Child Welfare in India in 1986 quoted in Gill [2011:6])
\end{abstract}

Conceptions of Early Childhood Care and Education (ECCE) present an integrated view of young children and their intertwining needs. Indeed the multifaceted nature of ECCE presents a promising opportunity for integration of services, which are distributed across multiple sectors of governmental delivery systems such as health, social welfare, women's affairs, community development and education (Gill 2011; Marfo 2011; Myers 1992; UNESCO 2006). A whole child perspective and the interconnectedness of the different dimensions of early development prompted Caldwell (1989) to coin the term 'educare' envisioning holistic and integrated ECCE that bridges the gap between early education and care (including health).

ECCE is the first critical step to laying a sound foundation of life and influences well-being throughout the life course. The ECCE phase spans the whole range of activities that promotes holistic care, development and socialisation of children such as education, health, nutrition, psycho-social, and emotional care and development (Irwin et al. 2007; UNESCO 2006, 2015). Additionally, the greatest and most lasting effects on child learning, health and development come from improvements in the capacity of parents to provide support to their children (Myers 1999). Poverty, poor maternal and child health, undernutrition and lack of early stimulation undermine children's development in the critical early childhood phase. Kenya, like many countries in sub-Saharan Africa, has an extremely high and disproportionate representation of young children who bear a great risk of failure to achieve their developmental potential because of limitations in health, nutrition, education and care services. This is accentuated in marginal spaces like urban poor locales and underscores the imperative of an integrated approach to ECCE for all children.

The current framing of ECCE policies and programmes has continually adopted a segmented approach to address the needs and secure the rights and well-being of young children. The conceptualisation of ECCE at policy, practice and research levels highlights the inadequacies inherent in separating these dimensions. In this paper, we trouble this artificial divide between 
and within the various dimensions in practice generally and for health and education specifically, which according to UNESCO (2015) are interwoven and are mutually reinforcing.

Indeed, the General Comment number 7 (GC7) was a response to the limited information in UNCRC reporting on holistic ECCE and the troubling focus of most reports on child survival indicators such as child mortality, immunisation and birth registration. Within child health, we problematise the dominant focus on survival needs within international and national policies. According to Gill (2011), at least $50 \%$ of UNICEF resources are invested in child survival, and almost the entire focus of the research, data and analysis is on access and utilisation of products and services. Research and programmatic attention on the social, emotional and cognitive aspects of child development, or on changes in social norms, community perceptions and participation, and other such qualitative measures, are conspicuous by their absence. This is consistent with the critique by Shonkoff (2010:365) of current ECD policies that focus more on '... health survival and departmentalisation of interventions' as well as inherent weaknesses in putting these policies to effect even when they are present. The push for a more expansive conception is thus prompted by the awareness that children are surviving but not thriving or that many of the survivors are developing far below their potential (GranthamMcGregor et al. 2007; Myers 1992).

Similarly, in early education, our standpoint is consistent with the push for a shift away from the constricted notion of learning confined largely to formal education, to a more expansive conceptualisation that encompasses the range of milestones encompassing stimulation strategies for physical, affective, cognitive and social development. These range from strategies to promote fine and gross motor competencies incorporating infant body massage as a crucial starting point, to contextual measures of intelligence which blend cognitive alacrity and social responsibility embedded in the indigenous everyday curriculum through learning by doing (Barry \& Zeitlin 2011). Such a focus would be inclusive of the home and community as foundational learning spaces with parents or caregivers as educarers, and a recognition of their fluid needs and range of local resources and learning tools. Additionally, we concur with UNESCO (2015), on the need for contextualised interventions that are anchored in meaningful, multi-sectorial collaborative exchanges to tackle the limited coordination of current fragmentary ECCE interventions.

We cast the segmenting process within a backdrop of glaring silences and gaps surrounding policy and practice for children aged between 0 and 3 years whose care is often relegated to the realm of households and the distributed care system of the extended family and community based nonstate systems (Okwany et al. 2011:12; Marfo et al. 2008). We articulate our arguments within critiques of the universality of the dominant ECCE narrative and its Eurocentric construction of childhood and care and the call for contextually responsive policy and practice based on respectful dialogue of the diversity of narratives
(Pence \& Nsamenang 2008; Marfo et al. 2008; Okwany et al. 2011). Our arguments in this paper respond to a focus on thriving within a holistic framing where the physical, emotional, social, cognitive and psychological needs are addressed in a comprehensive and complementary manner. In doing so, we not only take into account the 'whole child' but advance inclusive ECCE for 'all children'.

The rest of the paper is organised as follows: The introduction is followed by a contextual overview of ECCE in urban poor locales. We then outline the socio-ecological model, which is the conceptual framework that guided the analysis of findings. We also overview the qualitative methodology adopted in this study, which incorporated participatory, reflexive following ethical processes. This is followed by an analysis of findings in which we tease out and interrogate the artificial divide as well as the assumptions and silences inherent in the current ECCE health and education policies. We also illustrate the rich nuanced experiences of 'educarers' (parents, caregivers and community health workers as well as local-level care providers, both state and private practitioners). These provide contextual accounts which counter the dominant ECCE narrative. In the concluding section, we state imperatives for bridging the artificial divide between education and health in support of holistic, integrated ECCE policy and programmes.

\section{Contextualising ECD in urban poor locales}

According to UN-Habitat (2007) urban poverty in Kenya, as elsewhere in the developing world, is growing very fast and rapid urbanisation is identified as the greatest challenge for African countries, second only to the HIV and/or AIDS pandemic. $^{1}$ An estimated 60 million people join the urban population annually. The largest of this movement is witnessed in Africa where the majority of the population settles in pockets of urban poor locales (UNICEF 2012:2) and urban poor residents comprise an estimated $60 \%-70 \%$ of city populations. The latest slum population estimates in Kenya stand at 3138369 in 2009 and have increased from 862000 in 1980 (Kenya Bureau of Statistics 2009).

Urban poor locales are dynamic spaces where in-and-out migration is common, and they are characterised by systemic marginalisation and poor developmental outcomes for children (UNICEF 2012). Poor social service provisioning means that children have low immunisation, high malnutrition levels and stunting, as well as high rates of mortality, and weak birth registration systems that further exacerbate the invisibility of young children in these marginal spaces (Kyobutungi et al. 2008; Zulu et al. 2011). A study in Korogocho and Viwandani (adjacent slums to the study site) links infants' ill health to reduced or lack of breast milk and indicates that over $37 \%$ of children were not breast fed in the first one hour following their birth (Murage et al. 2011). Overall, the troubling health status of urban poor children 1.Of the urban residents in sub-Saharan Africa, $71.9 \%$ live in slums, the highest percentage in the world (UN Habitat 2007). 
has serious implications for early stimulation and learning of young children in these marginal locales.

Urban dwellers live in monetised economies and are susceptible to fluctuations in the cost of living and have few buffers to fall back on - increasing their vulnerability. Most residents depend on work in the informal sector and petty trade as way of generating income as well as kinship based savings and credit associations (APHRC 2002:12). They maintain tenuous links with extended family and there is mutual reciprocity whereby they send money to rural areas and receive food in return (Oxfam Great Britain 2009:28). The environmental problems facing developing countries are also increasingly associated with cities and urban poor locales where residents have insecure tenure and live in least desirable locations making them vulnerable to multiple shocks and risks.

These spaces also evince numerous interrelated deprivations including limited shelter, water and sanitation, food security and waste disposal Tacoli (2012) and because their locales are deemed illegal settlements, they have difficulty ensuring accountability from service providers. A high proportion of the urban poor population is young (and unemployed) with an estimated $60 \%$ of the urban poor population in Africa below 29 years of age (UN-Habitat 2007). This compounds the childcare contexts within which caregivers provide initial stimulation and holistic health care. Time-poverty is a keycompounding factor of caregiver's vulnerability and urban poverty often has a gendered dimension with women working for long hours and juggling their time between unpaid carework and poorly paid informal work that is time- and labourintensive. Indeed, women within these spaces do not have equitable access to work, safe living conditions, health, and educational assets as well as community leadership opportunities (Tacoli 2012:5). This has implications for effective care giving, scaffolding and stimulation of young children.

The government of Kenya has instituted a maternity and paternity leave policy Kenya Employment Act (2007), which has no transformative effect on gender roles in these locales in-terms of better support for children. This is because the policy is limited in many ways including the employer being the main financier of this leave with no state support/subsidy hence no effect on informal/self-employment patterns common among carers in these spaces. As there is no public childcare in support of working mothers, many women leave their children with older children or neighbours or on their own (Taffa \& Chepng'eno 2005:283).

Overall, limited state action creates a developmental void, which is filled by non-state actors both formal and informal including private providers of social services. The role of non-state actors while central, is also limited and insufficient because delivery is patchy, overlapping and fragmented and they compete for funding, lack coordination and oversight (Okwany 2010; Oxfam Great Britain 2009:28). Their services have thus not been adaptive to the changing needs of urban slum dwellers. Failure of policy processes to take into account the contextual and interwoven nature of child vulnerability and support systems highlights the need for integrated responsive ECCE interventions in these spaces.

\section{Conceptual lens: A socio-ecological model of care}

Our conceptual lens is the socio-ecological model, which challenges individual level approaches and afforded us a nuanced contextual analysis of ECCE practice and policy. According to Bronfenbrenner (1994:39) the childcare context is a series of nested systems from the most proximal - the microsystem, through the meso- and exosystems to the distal overarching macrosystem. The approach entails an examination of the bidirectional interactions in these systems which link the individual child and family to society, regional and (inter)national systems of policy and care.

The microsystem represents the immediate environment and the context of care within which a child interacts. This includes particular people, institutions or cultural norms that influence how they engage with their immediate environment and beyond. At the meso-level, the construction of gender is important for this research because society attaches roles and values to gender and this has repercussions for engagement and framing of males and females in caring roles and advancement of holistic ECCE. The macrosystem incorporates all the other systems and represents the cultural, policy and wider local and global aspects of society and how they interact to influence the individual child and households. These interactions are structured by social cultural factors and institutional norms, highlighting the crucial role of culture and policy at the macro-level, in stimulating, guiding and enhancing the intermediary systems on behalf of more effective parenting at the micro-level (Garbarino, Vorrasi \& Kostelny 2002).

The socio-ecological model enables us to examine the critical role that parents and caregivers play as 'educarers' and how their action is shaped by interactions between these ecological layers in both enabling and disabling ways. We also examine how they negotiate and assert their needs and the possible spaces for intervention. By so doing we are able to interrogate the processes that implicitly or explicitly function to sustain the dominant essentialising ideas that segment ECCE with a specific focus on the 'artificial' divide between health and education. We draw on our analysis to make a case for an approach in which care (health) and learning are holistic components of ECCE which affect and expand on the other and the entire early child development regime including nutrition, social protection, poverty and parental support. The model is also an important tool for analysis and organising ECCE interventions, which are responsive, contextualised and holistic. We utilise this model to argue for the need to situate children and educarers within wider socio-cultural and structural contexts in which individual and interpersonal ECCE practices and behaviours are embedded. 


\section{Methodological approach}

In staying true to contextually sensitive research methodologies that are critical to countering the dominant framing in ECCE research, we draw on the contention by Okwany and Ebrahim (2015) who challenge us to rethink epistemology and research methods in early childhood research in Africa. This is because 90\% of the world population's ECCE narratives do not inform the dominant narrative, which is the frame reference for many international childhood and childcare policies and programmes. To counter our assumptions and biases, we maintained a critical reflexive practice and orientation in research and analysis. For example, urban poor-based research has tended to reinforce a singular narrative of vulnerability and images of lack; however, these assumptions are challenged by the prevalence of rich childcare practices utilised by educarers in this study.

We adopted qualitative participatory approaches and engaged inquiry to highlight the situated ECCE experiences of caregivers and we positioned them as speaking subjects (ibid). We also reviewed relevant literature on early education and health polices in urban poor contexts. We selected Mukuru Kwa Reuben slum because it plays host to multiple non-state and state care providers. We used purposive and snowball sampling to select the study participants who comprised: 13 households, 3 state child health policy makers and 10 non-state (private registered and unregistered providers). Data collection techniques included: in-depth semi-structured interviews focus group discussions and participant observation. Data were recorded through note taking and tape recording. Field notes were transcribed and organised for ease of analysis.

From an ethical standpoint, we adhered to indigenous methodology and 'relational accountability', which calls for 'respect', 'reciprocity' and 'responsibility' in research (Wilson 2008:77). This approach helps the researcher to engage ethically and reflexively with the context, participants and the data produced throughout the research process. The approach was successful in enhancing rich interactive discussions with the study participants as opposed to extractive methodologies that reduce participants to passive research objects. We obtained ethical clearance on multiple levels first with the National Commission for Science, Technology and Innovation, followed by the Nairobi county office and the chief of the Mukuru Kwa Reuben area. Caregivers had a preference for providing verbal consent and we obtained written consent from the state and non-state health care providers. The consent spelt out the purpose of the study, and assurances of anonymity, confidentiality, noncoerced involvement.

Data analysis involved identifying themes of meanings related to difference and similarities in the care strategies of young children. These themes were clustered as sub-themes in order to categorise the strategies and patterns of provisioning and define overarching themes in articulation with literature from empirical research. A range of themes emerged including: ECCE practices at family, community and state level, counter constructions of childhood, resilience and coping practices. We ensured nuanced presentation of findings as much as possible showing patterns, contradictions and associations.

\section{Selectivity and segmentation within education policy and practice}

Kenya places relatively well in Africa among child-friendly states, with a robust legal and policy regime for protecting children UNICEF (2008c) and a long history of commitment to develop ECCE. The institutionalisation of ECCE in Kenya is a colonial heritage (Githinji \& Kanga 2011:131), and there is national adherence to international frameworks and conventions on ECCE to guide and inform policy and practice. The Children's Act and the National Plan of 1989/1993 domesticate these frameworks and conventions under the Ministry of Education Science and Technology. However, major gaps and inherent weaknesses in implementation persist underlying the limited state action in providing equitable ECCE services. Current interventions are fragmentary and diffuse with the private sector and nonstate actors as the key providers of services for young children including those who are 0-3 years of age Okwany et al. (2011). Indeed, many programmes are pre-primary education centres, which pay disproportionate emphasis to cognitive aspects of learning including didactic learning methods and exam-oriented curricula in preparation for formal primary school (UNESCO 2005:14). This reinforces and responds to the constricted conception of learning as formal education and has led to what Choi (2006) and others refer to as the 'schoolification' of early learning and stimulation as opposed to creative stimulation, socialisation and play. Critically, it points to a disproportionate focus on children over three years old and a lack of attention to the critical zero to three years age category.

This is consistent with the critique by Adala and Okwany (2009:2) of current conceptions of education within the narrow and limiting minimalist approach that confines and legitimatises learning within formal institutions thereby subjugating and devaluing other ways of knowing and intensifying inequities. We join them in supporting a maximalist approach to learning as put forth by Wain (2001) in which he proposes a learning society in support of responsive care giving. Similarly, Ebrahim (2010:82) exposes the shared dominant discourses, which frame teacher's interventions in ECCE centres in KwaZulu-Natal. These discourses which include biological, developmental and difference, constrain ECCE practices by homogenising experiences of children in spite of their differences in context, meaning making, childhood experiences and linguistic diversity. We also draw on Odora-Hoppers' (2004) powerful illustration of the alienating effects of adult literacy systems, which she contends function to constrain education within formal schooling and Western knowledge thus marginalising rich indigenous knowledge systems. As such, the home and 
community as foundational spaces for early learning and parents/caregivers as foundational teachers and educarers with an array of rich indigenous knowledge are silenced and marginalised. We argue for the need to retrace our steps and draw from indigenous knowledge to embrace contextualised and situated experiences of educarers.

\section{Selectivity and segmentation within health policy and practice}

Health care provisioning is the main mode of state interaction and state visibility for children aged 0-3 years. Kenya has adapted a plethora of global child health policies that relate to key Health Sector Reforms. They include: the Second National Health Sector Strategic Plan (NHSSP II) upon which the Kenya Child Survival and Development Strategy (CSDS, 2008-2015) is based, Community strategy for All 2006; Sector wide Approach (SWAP); Essential Health Package (MOPHS 2008:15). This strategy is implemented through a basic needs approach targeting marginalised groups like the urban poor locales to obtain access to services. Despite these policies, selectivity within health policy has been entrenched through the adoption of Selective Primary Health Care (SPHC) in 1982, which lays disproportionate emphasis on child survival (UNICEF 2008a:31). The identification of seven key cost-effective measures that were considered significant in lowering child mortality reveals this bias. They include Growth monitoring, Oral rehydration therapy, Breastfeeding, Immunisation, Food supplementation, Family Spacing and Female education. On top of these selected options is the Integrated Managements of Childhood Illness (IMCI) developed in 1992. This morphed into C-IMCI with the emphasis on community involvement. Further, compartmentalisation of health management is evident within the Department of Family Health Services where 0 to 3 years health policy formulation falls under various divisions. These include Divisions of Nutrition, Child and Adolescent Health, Reproductive Health and Immunisation.

We draw on the above to argue that the application of selective health care in marginalised contexts like urban poor locales problematises the child and caregivers rather than addressing the multiple complex interplay of social, political and economic structural failures underlying their deprivation (George 2010; Penn 2008; Woodhead 2006). We also concur with Rifkin and Walt (1986:562) who posit that the SPHC locates the professional health provider at the centre of interventions and change thereby marginalising the role of educarers as legitimate change agents in their contexts. Additionally, we find a disproportionate attention to illness and disease, which contrasts sharply with the PHC that emphasises a holistic approach to promoting health care (physical, emotional, social) and well-being not merely the absence of disease. Indeed, social and emotional paradigms have received minimal attention and the tendency has been to universalise the needs of children ignoring the multiplicity of contexts and life events (Woodhead 2006:10). Additionally, we contend that the nature of the community strategy advanced within SPHC aims, addresses selective needs through particular channels of demand or participation. There exists an overemphasis on specific health education that bears minimal attention to variances of knowledge and practice within contexts. Educarers are therefore 'schooled' into particular ways of providing care. We argue that not only have these selective health policies functioned to constrain caregivers' situated experience, they have also bypassed and undermined the fluidity of their hybridised local knowledge on early stimulation, learning, health and well-being.

We suggest that selectivity within education and health policy and practice entrenches the 'artificial' divide between these two areas and the dominant narrative of what is considered appropriate for enhancing the well-being of the child, prevails. This includes: notions on what is suitable learning and health care, who are privileged as legitimate care providers including teachers and health workers; privileging of particular learning and health care spaces such as schools and health facilities and the divide between different ministries in policy making and implementation. These selective processes make it difficult to pursue a holistic integrated ECCE for young children.

\section{Contextual accounts: 'Un-muting' holistic early childhood care and education in urban poor spaces}

In this section, we expose the nuanced experiences of children and their multiple educarers located in the urban poor locale of Mukuru kwa Reuben and reveal how their experiences counter the dominant narratives that often segment ECCE. A socio-ecological lens is critical in exposing the various inter-connections, interactions and bi-directional interactions between the micro, meso and macro levels of care for children aged 3 years and below. Our findings reveal the potential for holistic approaches to ECCE within these spaces. The prevailing normative narrative often frames urban poor contexts as defective spaces of deprivation and lack. However, our findings revealed that they are not merely sites of miserable poverty and violence but they can be lively and energetic places where the mixing of different cultures often produces new movements and levels of solidarity (Okwany 2010). Residents are highly organised, forming associations and social networks as part of collective processes for obtaining services, information, support and other resources. Within these spaces, we argue that educarers actively engage in the process of mutual exchange through which they learn and support each other.

In their study on orphan care and extended family support Abebe and Aase (2007:2062) point to the nuanced heterogeneity of household capacity, which range from economic capacity, emotional capacity to socio-cultural capacity. Drawing from this variability of capacity, our study findings reveal that households in urban poor locales like Mukuru kwa Reuben have a range of capacities beyond economic capital in support of childcare and well-being. These households still had sociocultural and the emotional capacity which are critical in 
developing 'psycho-social competencies' (ibid). Children were seen as a source of joy and were defined as a source of emotional and social strength for caregivers. They are viewed and constructed as a gift and a blessing especially in marriage, even though the meaning of marriage in this context is fluid and ranges from live in, customary unions to formal civil or religious unions. We highlight the notion of 'inter-generational contract' as coined by Abebe and Aase (2007:2065) to describe the role of children where they are seen as vessels that carry and transfer the family name and culture therefore enhancing familial and intergenerational linkage. These accounts reveal the interrelations between children and their educarers, which are vibrant, mutual and reinforced by adopting holistic conceptions of care. However, these interrelations are structured by the material, socio-cultural and spatial context inherent in urban poor locales and ultimately influence their lives.

Our findings show that though the majority of urban residents are rural immigrants, geographical separation does not sever ties with their extended families in their rural homes or ushago (common slang term for rural homes) where communication and mutual reciprocity persist. Engagement with kin in ushago (including grandparents and relatives) draws them into children's 'social-cultural socialisation' in the distributed care system. This is critical for identity and belonging as well as the child's social acceptance particularly in a context where communalism is privileged over individualism. More importantly, these exchanges facilitate opportunities for learning between children and their educarers, which is critical in enhancing holistic ECCE. This is consistent with the study by Barry and Zeitlin (2011:134), in the context of rural Senegal, which revealed the richness of the African traditional curriculum administered through 'orders' and 'observation' of caregivers. The study also encompassed holistic aspects of ECCE geared towards stimulating the child's socio-adaptive capabilities, motor, cognitive, linguistic, psychosocial, emotive and intellectual abilities.

Despite the material deprivations, urban poor locales facilitate emotional, physical, psychological, and cognitive development through co-shared and distributed childcare activities. The rented often one-roomed houses are grouped into plots of 8-12 houses, which are attached to each other wall to wall. This cramped living arrangement unlike gated middle class homes enhances close relationships and mutuality between educarers. With no state investment in childcare for working parents, a community network of neighbours, friends and older siblings provides care. Educarers revealed significant useful intercultural exchange on child stimulation, health and well-being, which was particularly useful for recent migrants to bond, build resilience and cope in these spaces. These interactions form a key part of the 'horizontal philanthropy' pervasive in marginal contexts with limited state provisioning (Okwany \& Ngutuku 2016).

The silencing, muting and marginalisation of these important care relations reinforces a risk model and a window through which exclusionary processes deprive children of family and community structures that can support holistic well-being. While recognising the critical place of positive local resources including these care relations, we caution against overvalorising them by emphasising the role of the state as the duty bearer in supporting poor families. In their study which examined social protection interventions for vulnerable children by non-state actors, Okwany and Ngutuku (2016) note that with widespread vulnerability, these interventions are often too 'microised' and 'projectised' and only help communities 'get by' but cannot tackle the structural forces that underpin child poverty (including support for integrated ECCE). This points to the need to entrench meaningful interactions between macro, meso and micro level action in the childcare ecology and highlights the primary role of macro-level structural forces in both driving absolute poverty and also providing avenues for addressing it.

\section{Marginal voices of educarers in urban poor locales}

Our interaction with the plurality of carers in the study site revealed that parents/caregivers, community, private and state care givers are continually involved in the intertwining roles of caring, and education. However, their roles are enabled, constrained, made dominant or marginal through institutional norms that assign and establish legitimacy of some forms of care over others. These institutional norms which function at all spheres of the micro, meso and macro levels include gender, legal and professional codes and norms. Our analysis of interactions and transactions between caregivers and service providers are significant in understanding the segmentation processes that occur across ECCE dimensions including between health and education and how they impact the holistic well-being of children 0-3 years. We therefore present the lived experiences of these marginalised educarers in this context.

Gender is a construct, that presents a social template where inscriptions of how to exist and identify as male or female are cast (Harcourt 2009:14). In the realm of ECCE, gender structures how males and females are incorporated into childcare spaces. Females are disproportionately assigned roles of nurturers, early stimulators or primary child carers within the household and in the community. This feminisation of care is also mirrored in the caregiving, learning and health childcare systems for 0 to 3-year-olds in which females predominate. The role of men as foundational teachers and carers is rendered invisible and factors that facilitate or constrain their roles remain unaddressed.

Men's narratives in Mukuru Kwa Reuben revealed that they are active participants in their children's lives despite their marginalised caregiving roles. Men (most of whom are young) in these contexts often bear a burdened masculinity because they are constructed as dangerous threats to society and they face a 'double marginality' (Okwany 2016:10). Our findings reveal that many men were active in their children's lives providing support by fetching water, assisting in household chores, providing social and economic security and assisting in childcare including stimulation and care. This means that 
some men were challenging the gendered norms that confine men's activities in the public and not the private sphere and feminises early caregiving. However, socio-cultural controls do not transform as fast to accommodate these men's changing roles, for example, men who engaged in what is considered feminised roles elicited curiosity, frowns, ridicule or admiration among women and fellow men.

We contend that while the role of men as educarers is important to them and their families, it was constrained by multiple vulnerabilities tied to their urban poor contexts. These vulnerabilities are attributable to both macro-structural forces that shape livelihoods as well as cultural norms that shape gender roles within the exosystem, mesosystem and microsystems of care. Our findings reveal that men in urban poor locales are engaged in casual employment or underemployment with insecure livelihoods, erratic remunerations, in monetised contexts of constant price upsurges and minimal shock buffers like guaranteed state social protection or informal insurance or savings schemes targeting men. Therefore, these men struggle to live up to male breadwinner forms of masculinities to salvage their social image. They engage in what Izugbara (2011) describes as 'masculine overcompensation' by taking up two to three jobs round the clock. This 'overcompensation' is dominant among men who possess minimal material assets and have insecure livelihood. Their vulnerabilities remain unaddressed because of the incorrect assumption that patriarchy benefits all men and constrains women. Indeed as noted by Okwany (2016) for young urban poor males, these homogenising assumptions gloss over the imperative of taking into consideration the context in which the plurality of the masculinities of young urban males is enacted. Left unattended, we argue that these vulnerabilities marginalise the experiences of males while further constraining women to the private sphere and intensifying their susceptibilities and those of their children.

Our findings also reveal an aspect of institutional norms which is regulation through codes and laws that define who is recognised as a legitimate care provider outside the household (micro-context). The common state interventions when engaging with non-formal providers identified by Tawfik, Northrup and Jones (2002:11) include: 'regulation, motivation, education/persuasion and negotiation'. Regulation is the most common way of interaction between state (macrolevel institutions) and these care providers (at the meso/microlevel) and their roles may be facilitated or weakened by the types of formal institutional norms that exist. The legitimacy of caregivers is pegged upon successful award of specific merits, for example, teachers and health caregivers have to pass particular assessments and thereafter acquire certification. Formal recognition by the state is important because it is accompanied by rewards like legality, capacity development, updates, useful networks, visibility in state statistics and supply of state commodities while non-formality/informality is often marginalised.
In Mukuru kwa Reuben, there are private-regulated faith-based organisations and private unregulated informal caregivers in day care centres and health clinics. Non-formal providers include uncertified medical practitioners, traditional healers, shopkeepers and drug vendors among others who provide unregulated care. Our study findings revealed that private informal health providers proliferate and are in high demand in these urban poor spaces because of limited state facilities. Additionally, they are perceived to be more accessible because of their positive interpersonal relationships with clients and their flexibility in terms of availability. Regulation leads to closure of these facilities, or penalties charged for non-adherence to the law. However, regular oversight is hampered by limited state outreach, which leads to the reopening of these facilities. This highlights the need to explore other methods of interacting with such providers to sort out and support quality care provisioning and holistic ECCE. To promote synergy between the provisioning of social services, we join with Okwany et al. (2011:108) who assert that better services are achieved through the interaction/ integration of indigenous health systems with public health systems.

Community participation through community strategies has been adapted in Mukuru Kwa Reuben. Community Health Workers (CHW) who are recruited and trained through programmes funded by external donors, ostensibly become the 'visible agents' who carry out activities of these 'invisible agents' (international agents). Tensions and high expectations exist between the CHW (meso-level) and some households (micro-level) whereby, some community members feel that these CHWs are policing them but cannot provide what they need. On their part, the CHWs feel that they need more incentives given the demanding roles they play, for example providing/paying transportation for sick patients who are unaccompanied. Often the contextual needs of children are predetermined revealing preconceived framing of these spaces as deficient and in need of 'saving' through selected de-contextualised segmented interventions.

Our analysis presents these educarers as 'speaking subjects' and we have made an attempt to shift the power arrangements that position parents and carers within these marginal locales as deficient and inadequate and instead validate them as active social actors in ECCE whose situated experiences provide valuable insight for holistic and transformative polices for children aged 0-3 years. Additionally, these rich nuanced experiences provide narratives, which counter the dominant institutional ECCE highlighting the diversity of ECCE narratives.

\section{Conclusion: Bridging the 'artificial' divide within and between health and education}

The rights of children aged 0-3 years to holistic well-being can be achieved by building bridges and synergies between and within health and education and addressing the assumptions 
that lead to segmentation and privileging of particular knowledge and practice in ECCE. The right to health, education and other ECCE rights are intertwined and symbiotic and depending on how they are framed, they may constrain or build on each other. We have revealed that health and early learning, stimulation and scaffolding of children in these locales are compromised by the segmentation and selective intervention in health and education specifically and ECCE policy generally. In this final section, we highlight several implications for strengthening an integrated approach to ECCE.

\section{Adapting lifelong learning for and with educarers in urban poor locales}

We draw on Bagnall's (2004) notions of 'progressive sentiment' on lifelong learning specifically 'Individual, democratic' and the 'adaptive progressive sentiments' to advance the recognition and support for and with educarers in their contexts. We see educarers as active participants and not just recipients of learning processes. They hold rich contextualised knowledge from their socialisation and from adaptive practice that they have acquired as they provide care despite the exigencies of their material contexts. The proposed approach enhances individual progressive sentiment with a commitment to individual growth and development towards freedom from ignorance, dependence, constraint and inadequacy. This is in response to changes of what they need and stages in life that they encounter in providing care and it is a continuous process. 'Democratic progressive sentiment' would support educarers and move them towards social action and advocacy to demand their rights from the state and other duty bearers thus entrenching equity, and social justice through participatory democracy. The space to claim their rights so as to improve their lives and their children exists in policy spaces in the form of community engagement strategies where state providers and locally based providers can engage in dialogue in a range of fora such as barazas (meetings held between chiefs - the most local level administrative arm of government and the people). 'Adaptive progressive sentiment' is also crucial because the urban space is one that is characterised by rapid demographic, sociopolitical and economic changes. This makes it imperative to support caregivers' adaptive capacities.

\section{Privileging contextually responsive early childhood care and education policy and practice}

The capacity of care provisioning and educarers in urban poor locales mainly family and community capital is stretched but not completely ruptured. This means that these local resources should be crowded in and supported with the state playing its critical role of tackling structural vulnerability. Okwany et al. (2011:128) argue for the imperative of challenging the dominant narrative of ECCE and advocate for its recognition of and engagement with the multiplicity of local narratives. We argue for critical engagement with the assumptions and silences that govern care and development policies for young children. We contend that a significant step is active engagement with constructions that decentre dominant framing by drawing on board the experiences of the range of educarers and providers.
The role of grounded research is critical in highlighting the contextually nuanced experiences of children, caregivers and providers within the pluralities of care contexts for responsive ECCE planning and provisioning. These policies must be attendant not only to the micro-dimensions of care but also the meso- and macro-structural forces that shape and influence provisioning, caregiving and childhood. Foregrounding diverse voices and experiences of caregivers and children in health, education and overall well-being is crucial for just and equitable policy and action. Nagasawa and Swadener (2013:53) remind us to openly engage with tensions and create spaces where counter dialogues do emerge and are heard. These tensions exist within marginal care spaces like the study context through the variable ways caregivers negotiate their roles. Our discussion has shown that the continued artificial divide and fragmented ECCE provisioning is a key systemic deficit in policy approaches to tackle marginalisation. We contend that a competent integrated systems approach rooted in local experiences of caregivers and providers is critical in efforts to move progressively towards contextually responsive and holistic ECCE policy action.

\section{Acknowledgements Competing interests}

The authors declare that they have no financial or personal relationships which may have inappropriately influenced them in writing this article.

\section{Authors' contributions}

A.M. was responsible for developing the research design and data collection under supervision of A.O. The paper was written collaboratively by A.M. and A.O.

\section{References}

Abebe, T. \& Aase, A., 2007, 'Children, AIDS and the politics of orphan care in Ethiopia: The extended family revisited', Social Science \& Medicine 64(10), 2058-2069. $\mathrm{http}: / / \mathrm{dx}$.doi.org/10.1016/j.socscimed.2007.02.004

Adala, A. \& Okwany, A., 2009, 'From schooling for some to lifelong learning for all: A new paradigm for education and development in Africa', in M. Amutabi \& M. Oketch (eds.), Studies in lifelong learning in Africa: From ethnic traditions to technological innovation, pp. 279-314, Edwin Mellen Press, New York.

African Population and Health Research Centre (APHRC), 2002, Health and livelihood needs of the residents of informal settlements in Nairobi City, Occasional Study Report, APHRC, Nairobi.

Bagnall, R.J., 2004, Cautionary tales in the ethics of lifelong learning policy and management: A book of fables, Kluwer Academic Publishers, Dordrecht.

Barry, O. \& Zeitlin, M., 2011, 'Senegal's traditional and modern curriculum for children aged $0-3$ years', in A.B. Nsamenang \& M.S. Tchombe (eds.), Handbook of African educational theories and practices: A generative teacher education curriculum pp. 125-137, Presses Universitaires d'Afrique, Yaounde, Cameroon.

Bronfenbrenner, U., 1994, 'Ecological models of human development', in M. Gauvain, and M. Cole (eds), Readings on the development of children, 2 nd edn., pp.37-43.

Caldwell, B.M., 1989, 'All-day kindergarten: Assumptions, precautions, and overgeneralizations', Early Childhood Research Quarterly 4(2), 261-266. http://dx.doi.org/10.1016/S0885-2006(89)80007-9

Choi, S.H., 2006, Bite off only as much as you can chew': Gambia's policy for early childhood, Policy briefs on Early Childhood De, 34, UNESCO, Paris.

Ebrahim, H., 2010, 'Dominant discourses of teachers in early childhood education', Perspectives in Education 28(4), 80-87.

Garbarino, G., Vorrasi, J.A. \& Kostelny, K., 2002, 'Parenting and public policy', in M.H. Bornstein (ed.), Handbook of parenting: Practical issues in parenting, vol. 5, pp. 487-507.

George, S., 2010, 'Wasted childhoods? Beyond the pathologization of poor children and their families', in The doors of perception: Viewing anthropology through the eyes of children, Department of Social and Cultural Anthropology, Vrije Universiteit, Amsterdam, 30th September to 1st October. 
Gill, R., 2011, 'ECD in the international development context: Principles for holistic and inclusive policies and practice', in building peaceable communities: The power of early childhood, UNA Global Biennial Conference, Amsterdam, May 12th to 14th May.

Githinji, F. \& Kanga, A., 2011, 'Early childhood development education in Kenya: A literature review on current issues', International Journal of Current Research 3(11), 129-136.

Grantham-McGregor, S., Cheung, Y.B., Cueto, S., Glewwe, P., Richter, L., Strupp, B. et al., 2007, 'Developmental potential in the first 5 years for children in developing countries', The Lancet 369(9555), 60-70. http://dx.doi.org/10.1016/S01406736(07)60032-4

Harcourt, W., 2009, Body politics in development: Critical debates in gender and development, Zed Books, London.

Irwin, L.G., Siddiqi, A. \& Hertzman, C., 2007, Early childhood development: A powerful equalizer: Final Report, HELP, University of British Columbia, Vancouver.

Hoppers, C.O., 2004, 'Indigenous knowledge systems: The missing link in literacy, poverty alleviation and development strategies in Africa', Africa Insight 32(1), 3-7.

Izugbara, C., 2011, What about men? APHRC examines the practices of urban poor men, Africa Population Health and Research Centre, Nairobi

Kenya Bureau of Statistics, 2009, Census report population and Housing, Government Press, Nairobi

Kenya Employment Act, 2007, Revised edition, 2012, National council for law reporting, Government Press, Nairobi.

Kyobutungi, C., Zibara, A.K., Ezeh, A. \& Ye, Y., 2008, 'The burden of disease profile of residents of Nairobi's slums: Results from a demographic surveillance system', Population Health Metrics 6, 1. http://dx.doi.org/10.1186/1478-7954-6-1

Marfo, K., (2011), 'Foreword', in A. Okwany, E. Ngutuku \& A. Muhangi, The role of local knowledge and culture in child care in Africa: A sociological study of several ethnic groups in Kenya and Uganda, Mellen Press, London.

Marfo, K., Biersteker, L., Sagnia, J. \& Kabiru, M., 2008, 'Responding to the challenge of meeting the needs of children under 3 in Africa', in M. Garcia, A. Pence, J. Evans (eds.), Africa's future, Africa's challenges: Early childhood development in subSaharan Africa, pp. 201-222, World Bank Publications, Washington, DC.

Ministry of Public Health and Sanitation (MOPHS), 2008, Child survival and development strategy, Afya House, Nairobi.

Murage, K.E., Madise, N., Forso, J.C., Kyobutungi, C., Mutua, M., Gitau, T.M. et al., 2011, 'Patterns and determinants of breastfeeding and complementary feeding practices in urban informal settlement', BMC Public Health 11, 396. http://dx.doi. practices in urban informal settlem
org/10.1186/1471-2458-11-396

Myers, B.L., 1999, Walking with the poor: Principles of transformational development, Orbis Books, Maryknoll, NY.

Myers, R., 1992, The twelve who survive: Strengthening programmes of early childhood development in the third world, Routledge, New York.

Nagasawa, M. \& Swadener, B.B., 2013, 'Glocalization, neoliberal policies, and early childhood in Kenya and indigenous communities in the United States', He Kupu 3(2), 43-57.

Okwany, A., 2010, 'Universal primary education and social exclusion in Kenya and Uganda', in N. Awortwi \& A. Okwany (eds.), Issues in social development and local governance in Uganda, pp. 131-154, Shaker Publishing BV, Maastricht.

Okwany, A., 2016, 'Gendering youth: Decentering male in youth discourse', in M. Ntarangwi (ed.), Youth and social transformation in Africa, CODESRIA, Dakar.

Okwany, A. \& Ebrahim, H., 2015, 'Rethinking epistemology and methodology in early childhood research in Africa', in A. Farrell, S.L. Kagan \& K. Tisdall (eds.), Handbook of early childhood research, pp. 432-448, Sage, London.
Okwany, A., Muhangi, A. \& Mulongo, E.M.N., 2011, The role of local knowledge and culture in child care in Africa: A sociological study of several ethnic groups in Kenya and Uganda, Edwin Mellen Press, New York.

Okwany, A. \& Ngutuku, E.M., 2016, 'Social protection and citizenship rights of vulnerable children: A perspective on interventions by non-state actors in western Kenya', in N. Awortwi \& W. Gregor (eds.), Governance below the state: Non-state social protection in Africa. Palgrave Macmillan, London.

Oxfam Great Britain, 2009, Urban poverty and vulnerability in Kenya: Background analysis for the preparation of an Oxfam GB urban program focused in Nairobi, Oxfam BG Kenya Program, Nairobi.

Penn, H., 2008, Early childhood education and care in Southern Africa. A perspective report, CfBT Education Trust, Berkshire, pp. 1-38.

Pence, A. \& Nsamenang, B., 2008, A case for early childhood development in subSaharan Africa, Working papers in early childhood development, No. 51, Bernard van Leer Foundation, The Hague, the Netherlands.

Rifkin, S.B. \& Walt, G., 1986, 'Why health improves: Defining the issues concerning "comprehensive primary health care" and "selective primary health care",', Socia Science \& Medicine 23(6), 559-566. http://dx.doi.org/10.1016/0277-9536(86) S0149-8

Shonkoff, J., 2010, 'Building a new biodevelopmental framework to guide the future of early childhood policy', Child Development 81(1), 357-367. http://dx.doi. org/10.1111/j.1467-8624.2009.01399.x

Tacoli, C., 2012, Urbanization, gender and urban poverty: Paid work and unpaid care work in the city. Urbanization and emerging population issues, Working paper 7.IIED and UNFPA, London.

Taffa, N. \& Chepng'eno, G., 2005, 'Determinants of health care seeking for childhood illnesses in Nairobi slums', Tropical Medicine and International Health 10 240-245. http://dx.doi.org/10.1111/j.1365-3156.2004.01381.x

Tawfik, Y., Northrup, R. \& Jones, S.P., 2002, Utilizing the potential of formal and informal practioners in child survival: Analysis and summary of promising interventions, USAID, Washington, DC, pp. 1-35.

UNESCO, 2005, Policy review report: Early childhood care and education in Kenya, Early childhood and family policy series no. 11, UNESCO Education Sector, Paris.

UNESCO, 2006, Strong foundations: Early childhood care and education, UNESCO, Paris.

UNESCO, 2015, Investing against evidence: The global state of early childhood care and education, UNESCO, Paris.

UN-Habitat, 2007, The state of the world's cities 2006/7, Earthscan, London.

UNICEF, 2008a, The state of the world's children: Child survival, UNICEF, New York.

UNICEF, 2008b, Tracking progress in maternal, newborn and child survival. The 2008 report, UNICEF, New York.

UNICEF, 2008c, UNICEF Child Protection Strategy, UNICEF, New York.

UNICEF, 2012, The state of the world's children. Children in an urban world, UNICEF, New York.

Wain, K., 2001, 'Lifelong learning: Small adjustment or paradigm shift?', in D.N. Aspin, J. Chapman, J. Hatton \& Y. Sawano (eds.), International handbook of lifelong learning, pp. 183-198, Springer, New York.

Wilson, S., 2008, Research is ceremony: Indigenous research methods, Fern Publishing, Black Point, NS.

Woodhead, M., 2006, 'Changing perspectives on early childhood: Theory, research and policy', International Journal of Equity and Innovation in Early Childhood 4(2), 1-43.

Zulu, E.M., Beguy, D., Ezeh, A.C., Bocquier, P., Madise, N.J., Cleland, J. et al., 2011 'Overview of migration, poverty and health dynamics in Nairobi City's slum settlements', Journal of Urban Health 88, 185-199. http://dx.doi.org/10.1007/ s11524-011-9595-0 